\title{
Perfore İleal Divertikül
}

\author{
Perforated Ileal Diverticulum
}

\section{Eyüp PİRCANOĞLU1, Gülçin AYDIN², Serdar CİVELEK¹, Oktay AYDIN¹,}

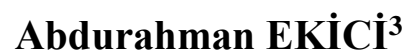 \\ ${ }^{1}$ Gaziantep Dr.Ersin Arslan Devlet Hastanesi Genel Cerrahi Bölümü, GAZİANTEP \\ ${ }^{2}$ Gaziantep Çocuk Hastanesi Anestezi ve Reanimasyon Bölümü, GAZİANTEP \\ ${ }^{3}$ Gaziantep Dr.Ersin Arslan Devlet Hastanesi Anestezi ve Reanimasyon Bölümü, GAZIANTEP
}

\begin{abstract}
ÖZET
İleum divertikülü insidansı \%0.001 olarak tesbit edilmiş olup, nadir görülen bir durumdur. Klinikte sağ alt kadran ağrısı ve enflamasyona sekonder lökositoz ile bulgu vermekte, ince barsak tıkanıklığı, kanama, volvulus ve perforasyon gibi komplikasyonlara sebep olabilmektedir. Akut karın tanısı ile operasyona alınan 18 yaşında erkek hastada saptanan perfore ileal divertikül olgusunu sunuldu.
\end{abstract}

Anahtar Kelimeler: İleum divertikülü, akut karın, perforasyon

\section{GíRiş̧}

İleum divertikülü çok nadir görülen bir durum olup insidansı \%0.001 olarak tesbit edilmiştir (1). İnce barsak tıkanıklığı, kanama, volvulus ve perforasyon gibi komplikasyonlara sebep olabilmektedir (2). Klinikte genellikle sağ alt kadran ağrısı ve enflamasyona sekonder lokositoz ile bulgu vermektedir. Ayırıcı tanılar arasında Meckel divertikülü, akut apandisit ve Crohn hastalığı gibi durumlar yer almakta olup, tanıda abdominal ultrasonografi (USG) ve abdominal bilgisayarlı tomografi (BT) yardımcı olabilmektedir (3-4). Akut karın tanısı ile operasyona alınan 18 yaşında erkek hastada saptanan perfore ileal divertikül olgusu sunuldu. 
Karın içerisinde yaklaşık 1 lt serohemorajik sıvı olduğu görüldü. Apandiks ödemli ve hiperemik olmakla beraber perforasyon olmadığı görüldü. Karın eksplore edildi. Terminal ileuma yaklaşık $20 \mathrm{~cm}$ mesafede ince barsak mezosunda yaklaşı $10 \mathrm{~cm}$ lik loküle sıvı kolleksiyonu olduğu görüldü. Mezo açıldığında ileal içerikle karışık pürülan karakterde mayi drenajı oldu. İncelemede mezo içerisine gömülü yaklaşık $3 \times 4$ cm'lik

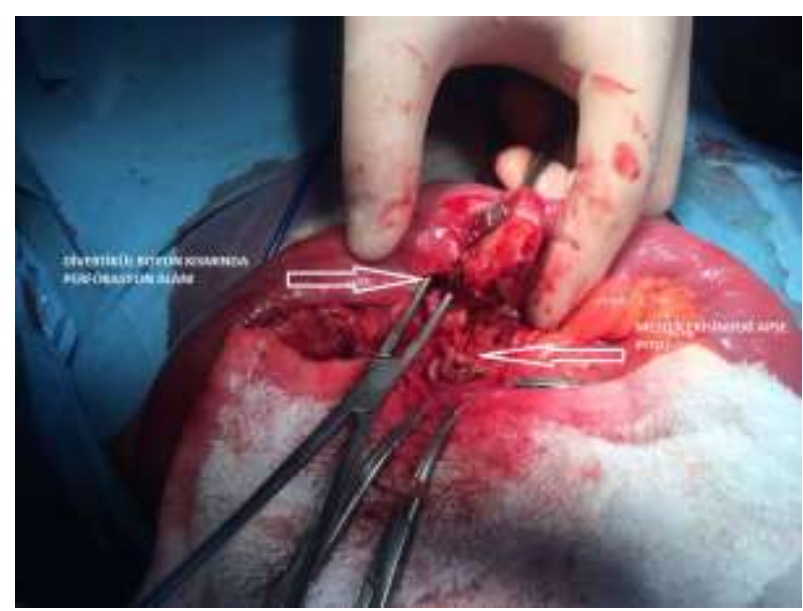

Resim 1: Terminal ileumda, boyun kismından perfore olmuş ileal divertikül.

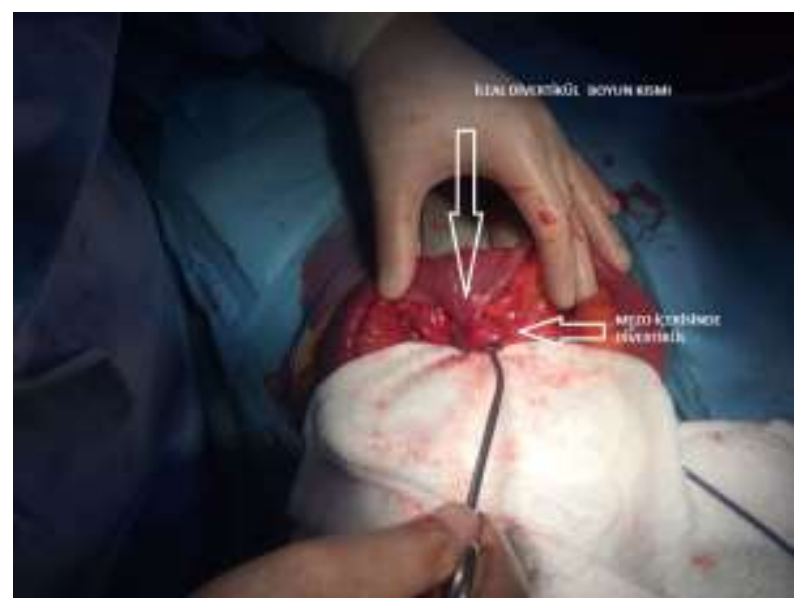

Resim 2: Terminal ileumda, incebarsak mezosu içerisinde ileal divertikül. ileal divertikülü olduğu, divertikül boyun kısmından perfore olduğu, mezo içerisinde apse oluşturduğu görüldü (Resim 1,2). Karın içinde yaygın peritonit hali yoktu, divertiküler segment mezosu ile eksize edilerek uç uca anastomoz yapıldı, apendektomi eklendi. Postoperatif dönem sorunsuz geçen hasta şifa ile taburcu edildi.

\section{TARTIŞMA}

İnce barsak divertikülleri duodenumda, jejenum ve ileuma oranla daha s1k görülmektedir. İleal divertiküller oldukça nadir olgular olup toplumda $\% 0.001$ oranında görülmekte ve sıklıkla çekilen baryumlu grafilerde tesadüfen saptanmaktadır (5). Kadın ve erkekte görülme sıkılığı açısından fark olmayıp genellikle kolon divertikülleri ile birlikte görülmektedir (6).

İleal divertikülleri primer olabileceği gibi Crohn hastalığı sonrasında, tüberküloza sekonder ve geçirilmiş ince barsak cerrahisi sonrasında da oluşabilmektedir (7). Genellikle ileal divertiküller asemptomatik olup \%10 kadarı semptom vermektedir (11). En sık görülen semptomlar dispepsi, gelip geçen kısa süreli karın ağrıları ve malabsorbisyona bağlı semptomlardır. İleal divertiküller; ileal obsturuksiyon, perforasyon, volvulus, divertikülit ve kanama komplikasyonları oluşturabilirler. İleal diveritkülü olan hastalarda kanama, perforasyon ve obstürüksiyon oranı \%6.5-10.4 arasında görülmektedir. Akut komplikasyonlarda mortalite \%25-50'e kadar çıkabilmektedir (11-12). Bunun yanında Meckel divertikülü de ayrıcı tanıda yer almaktadır (7). Meckel divertikülü sıklıkla 2 yaş üzerindeki çocuklarda ağrısız gastrointestinal kanama ya da divertikülit tablosu ile belirti vermektedir. Meckel divertikülü gerçek bir divertikül olup terminal ileumda, ileumun anti mezenterik yüzünde yer almaktadır.(8) Meckel divertikülleri ileum mezosu içerisinde olmamaları ile ancak cerrahi sırasında ileal divertiküllerden ayrilabilmektedir (9-10) 
İleal divertikül tanısı acil durumlarda en güvenilir olarak bilgisayarlı tomografi ile konulabilmektedir (4). Bilgisayarlı tomografi bulgusu olarak ileal duvarda incelme, mezoda enflamasyona bağlı olarak kirlenme, perforasyon halinde batın içinde serbest hava ve sıvı görülmesi ve son olarak divertikülün bilgisayarlı tomografide direkt olarak görülmesidir (13). Bilgisayarlı tomografide çekum ve apendiksin de görülmesi hem ayrıcı tanıda hem de cerraha yapacağı insizyon için fikir vermektedir. Bunun dışında çekilecek PAAC ve ADBG perforasyon varlığında yol göstericidir. Abdominal ultrasonografide batın içinde kolleksiyon ve sıvı seviyesi görülmesi. İnce barsak mezosunda kalınlaşma ve enflamasyon görülmesi, eş zamanlı olarak apendiksin değerlendirilmesi yol göstericidir.

\section{KAYNAKLAR}

1. Sloan GM, Vineyard GC. Perforated diverticulum of the ileum. Am J Gastroenterol. 1980; 74: 447-50.

2. Fisher JK, Fortin D. Partial small bowel obstruction secondary to ileal diverticulitis. Radiology. 1977; 122: 321-22.

3. Ferguson JA, Ramin JE, Slusher HE. Diverticulosis of the terminal ileum: case report. Mil Med. 1983; 148: 551-52.

4. Macari M, Balthazar EJ, Krinky G, Cao H. CT diagnosis of ileal diverticulitis. Clin Imaging. 1998; 22: 243-45.

5. Parulekar SG. Diverticulosis of the terminal ileum and its complications. Radiology. 1972; 103: 28387.

6. Hibbeln JF, Gorodetsky AA, Wilbur AC. Perforated jejunal diverticulum: CT diagnosis. Abdom Imaging. 1995; 20: 29-30.

7. Jones D, McMillin R, Greene F. Complications of acquired diverticula of the ileum. Am Surg. 1983; 49: 218-20.
8. Boneval C, Aksoyek S, Salman T, Celik A: Meckel diverticulum in childhood. A review of 76 cases. Med Bull Ist. 1998; 31: 2.

9. Bani-Hani KE, Shatnawi NJ. Meckel's diverticulum: Comparison of incidental and symptomatic cases. World J Surg. 2004; 28: 917 20.

10. Mackey WC, Dineen P. A fifty year experience with Meckel's diverticulum. Surg Gynecol Obstet. 1983; 156: 56-64.

11. Pfister R, Letourneau JG. CT imaging of acute right lower quadrant disease. AJR Am J Roentgenol. 1997; 168: 411-16.

12. Lieberman JM, Haaga JR. Computed tomography of diverticulitis. J Comput Assist Tomogr. 1983; 7 : 431-33.

13. Severin S, d'Alincourt A, Redon H, Hamy A, Mathon G, Lerat F. Small bowel diverticulitis: the role of CT. J Radiol. 2003; 84: 47-9. 